deed, if I had not previously determined to take that bone as my guide, I certainly should not have come upon the artery with equal accuracy. During the motions of the neck, caused by the unsteadiness of the patient, the artery followed this bone; hence the latter was always an unerring guide. Some inconvenience was caused by the yielding of the side of the pharynx upon which the artery may be said to lie, for the parts sank, as it were, under the knife and forceps, and rendered it difficult to proportion the degree of pressure employed in using them. On this account $I$ found it necessary to cause an assistant to press gently, during the operation, on the opposite side of the throat.

It is evident that the effects upon the brain of a ligature of the external carotid artery will be altogether different from those which result from tying the common carotid. When the latter artery is tied, there will be, at least for a time, a greater or lesser diminution in the quantity of blood sent to the brain, whereas, when a ligature has been applied to the external carotid, it may be presumed that the brain will receive at least, immediately after such a ligature, a greater supply of blood. This will perhaps account for the headach and great drowsiness which succeeded the operation in this case, and which for three days continued to be very remarkable. It may probably also afford an explanation of the irritability of the stomach, though it is more likely that this symptom resulted from the division of those numerous ramuscules of the sympathetic nerve which surround the external carotid. There were certainly no nerves or vessels, except the external carotid itself, included in the ligature.

Such are the observations $I$ wished to make on the case of Dunn, and I hope to deliver a lecture to you shortly on the case to which I have alluded in the commencement of the present lecture.

TWO CASES OF

\section{FATAL ENTERITIS,}

CAUSED BY HARDENED FECULENT MAT. TER IN THE APPENDIX CAECI.

\section{To the Editor of The LANCET.}

StR,-The accompanying cases are, we believe, by no means common. Should you think them worth inserting in THE LANCET, they are much at your service.

We are, Sir, your obedient servants,

T'humpson and Baller.

Westerham, Feb. 15th, 1834.
CASE I.-April 30, 1832, J. H., aged 10 years, a robust and healthy boy, complained suddenly of a pain in his bowels, referred chiefly to the right iliac region. The pain, although continued, did not excite much attention till the evening of the 2rid of May, when a medical gentleman residing in the house prescribed some aperient medicines and fomentations. The following morning, May 3rd, we were requested to see him, and found the abdomen exceedingly tense, and painful on pressure, but mostly so in the situation of the caput coli. The bowels had been freely relieved by the medicines; the motions were liquid and natural in appearance; pulse 120 and small; great anxiety of countenance. Recourse was immediately had to copious bleeding, leeching, fomentations, \&c., but without any mitigation of the symptoms. He still referred his sufferings chiefly to the caput coli. Vomiting, distention of the abdomen, \&c. supervened, and he died on the following morning, May 4th.

Examination post mortem. - On laying open the abdomen, the peritoneum presented marks of most intense inflamma. tion; the omentum was glued to the adjacent parts by recent adhesions ; the interstices of the bowels were filled by coagulable lymph. As we approached the cacum, the disease appeared to have raged with increased severity, and upon examining that part more minutely, we found the appendix vermiformis in a state of gangrene, containing within it a substance about the size of a cherry-stone, which proved to be a portion of hardened feculent matter.

CAse 2.-February 8th, 1834. C. U., aged 14 years, of delicate constitution, but apparently in good health, was attacked early in the morning with vomiting. The preceding day he had taken unusually active exercise, had gone to bed well, and referred his sickness to something he had eaten at dinner. He complained of no pain in his bowels, nor had they been constipated; but the abdomen was slightly tender on pressure. Towards evening the symptoms of abdominal inflammation became more fully developed, and were met, during that night and the following day, by the most active treatment, such as general and local bleeding, fomentations, enemata, \&c., but without any decided benefit. The vomiting ceased; he was able to retain anything upon his stomach, and he complained of no pain except on pressure. Still the tenderness continued to increase, particularly towards the right iliac region. Nothing passed through his bowels; the abdomen became distended, 
and on the morning of the 10th death put an end to his sufferings.

Examination post mortem.-On laying open the abdomen, the omentum was seen drawn towards the creum, a small portion adhering to that bowel, and in a state of gangrene. The small intestines were exceedingly distended with air, and exhibited marks of great inflammation. They contained very little feculent matter, and no stricture was found in them. The large intestines had been cleared by the enemata. Upon approaching the cacum, the marks of inflammation became more intense; coagulable lymph was thrown out in abundance; the appendix vermiformis was found adhering to the subjacent parts, in a gantrrenous state, and distended by a portion of feculent matter, of the size of a small nutmeg, and nearly as hard.

\section{INVENTION OF THE PERCUTEUR.}

ClAiMS OF MR. WEISS.

\section{To the Editor of The Lancet.}

Srr,-Having read in The Laxcet of Feb. 15th, a letter from Mr. Fergusson, claiming the merit of an improvement upon the lithontriptic percuteur, I am compelled in self-defence to trouble you with this letter, and I request the favour of its insertion as an act of justice.

It is now nearly ten years since $I$ invented a curved instrument for breaking calculi in the bladder by means of a screw; but in consequence of an objection made to it by an eminent member of the profession, and the great demand for the straight boring instrument, I laid it aside, and no further notice was taken of it. Some time ago, however, I showed it to Baron Heurteloup, who immediately adopted the idea, and shortly after produced an instrument differing from nine in the substitution of a hammer for a screw; and, trusting to the little notice that had been taken of my invention, claimed it as his own. The Baron's instrument, I admit, may be an improvement upon mine, more particularly where hard calculi are to be broken, but this of Mr Fergusson's is nothing more than an alteration, and that an inefficient one, as every one knows that a rack is greatly inferior in powcr to a screw, Mr. Fergusson is quite welcome to all the credit of his alteration; but he does not seem content with that, for he appears to wish to deprive me of my share in the invention, else why the ostentatious mention of the French maker, of himself and countryman, while I am not even named. This may arise from ignorance, though it is not very likely, as there is scarcely a professional man in the country but reads The Lancet ; and those who are interested in the progress of lithotrity, may remember that in the controversy between Baron Heurteloup and Mr. Costello before the Westminster Mcdical Socicty (see LANCET, Dec. 15th, 1832), my claim to the original invention of the instrument was allowed, and that I subsequently had occasion to assert my claim in the same publication, Sept. 14th, 1833, in consequence of an attempt to deprive me of the credit of it by one of the Baron's friends. The fact, that neither of these statements has been disputed, must be, I think, confirmatory to any one not blessed with obliquity of vision,- a complaint frequently attendant upon prejudice. However, if any further proof is required, I can produce a letter from $\mathrm{Mr}$. Brodie, stating the fact of my having shown him my insirument niue years ago, and of his having broken a hard calculus with it; this was more than five years before the Baron Heurteloup brought forward his instrument.

As nothing redounds more to the honour of a professional man, than the being enabled to relieve suffering humanity by a new and more safe operation, so there is nothing that gives the mechanic greater pleasure than success in inventing or improving an instrument for that purpose; and where a professional man finds a mechanic willing to save him trouble and expense, by spending both time and money on the completion of an instrument upon the chance of success to which alone he looks for his remuneration, the least he can do is to give him the credit of the invention. In this respect $\mathrm{I}$ have been fortunate; Sir Astley Cooper, Mr. Brodie and other eminent surgeons, have, I am proud to say, given me full credit for my inventions; but others, whose names I could mention, have not had sufficient generosity, and fearful of its being known that they had received the slightest assistance, have tried to suppress my claim, though hitherto without effect. Had Mr. Fer. gusson been ingenuous, he would have acknowledged that his instrument was only a modification of mine; but ingenuousness, I fear, is not his forte, and I should not be surprised if, upon the failure of the rack, he were to put forth a modification of it by means of a screw; but with your assistance I will screw him down to his own rack.

I am, Sir, Your obedient servant, Joan Werss.

London, 62, Strand Feb. 24, 1834. 